\title{
Taxonomy Category Name
}

National Cancer Institute

\section{Source}

National Cancer Institute. Taxonomy Category Name. NCI Thesaurus. Code C115543.

The preferred word(s) used to describe a taxonomic category. 